\title{
A NTIROUFFAER.
}

\section{NASCHRIFT OP HET RAPPORT VAN 16 APRIL 1904 OVER DEN AGRARISCHEN RECHTSTOESTAND DER INLANDSCHE BEVOLKING OP JAVA EN MADOERA}

DOor Mr. C. VAN VOLLENHOVEN.

1. De weg om achter "het oude Javaansch-agrarische recht te komen zou slechts in twee gevallen zijn uitgangspunt kunnen vinden in de rechtsopvattingen en rechtsinstellingen der Javaansche vorsten. Vooreerst, indien het vorstenbestuur van Java even oud ware als, of zelfs ouder dan, het bestaan van een grondenrecht der bevolking; indien dus het vorstenbestuur op Java een vacuum van grondenrecht hadde aangetroffen, en met zijn eigen denkbeelden en maatregelen dat vacuum hadde ingevuld. Deze onderstelling zal wel niemand voor zijn rekening willen nemen; een streek trouwens als het zuiden van Banten, die nooit vorsten-gezag heeft gekend, heeft nochtans een grondenrecht, verwant aan dat van heel het verdere Java. Het tweede dier onderstelde gevallen zou zich voordoen, indien wel is waar een ouder grondenrecht der bevolking aan het Javasche vorstenbestuur ware voorafgegaan, doch door de kracht van dit vorstenbestuur totaal ware verdrongen. Zelfs zij, die den vorsten zulk een kracht toekennen ten aanzien van het ommeland hunner hofstad (het kerngebied der rijken Mataram, Tjerbon, Banten), zullen huiverig zijn te gelooven, dat tot in de verste hoeken van hun gebied de vorsten bij machte waren een oudinheemsch volksrecht te verdringen. Derhalve rest geen andere methode dan eerst te zoeken naar een agrarisch recht der Java-bevolking, los van eenigen invloed van vroegere of latere vorsten en uitsluitend samenhangend met de inrichting van haar dēsa's, en daarna te vragen, in hoever nu het recht der vorsten wijzigend kan hebben ingewerkt. Voor Bali en voor Lombok is, in de hand van uitnemende deskundigen, 
deze methode proefhoudend gebleken; en ook voor andere streken met vorstenbestuur op of buiten Java is dit de eenige weg.

2. Het antwoord op de vraag naar het oudinheemsche grondenrecht der bevolking van Java wordt zeer vergemakkelijkt door wat men weet van de rest van Indonesië. Niemand kan de vier deelen (vijf boekdeelen) "Pandecten van het adatrecht" (1914-1918) doorlezen zonder te zien, dat het agrarisch volksrecht van Java precies dezelfde hoofdtrekken toont als het agrarisch volksrecht der overige eilanden. Beschikkingsrecht, genotrecht, voorkeurrecht, inlandsch bezitrecht, zamel-, weide- en jachtrecht, pandrecht, recht van deelbouw en veldhuur, enz. enz., - het is tot in bijzonderheden strookende met wat wij afweten van Sumatra, Borneo, Celebes, de groote Oost en Bali. Zelfs het Soendaland, waar -- evenals in Atjèh - het beschikkingsrecht zoogoed als verdwenen is en het inlandsch bezitrecht dientengevolge tot een oostersch eigendomsrecht nadert, laat toch zijn grondenrecht alleen verklaren op deze algemeen-Indonesische basis.

3. Daarentegen vindt niet één dezer Indonesische trekken van het Javasche grondenrecht verklaring in het grondenrecht der vorsten. Noch de beschikkingskring der dorpen, noch de recognitie of pamesi, noch de aansprakelijkheid der dēsa, noch het rechtsgevolg van boschafbakening hier en ginds, noch de bijstand van het dorpsbestuur bij gewichtige grondtransacties, - noch een der inheemsche rechten op water kan worden verklaard uit 's vorsten pretensie, dat hij eigenaar is van allen grond en van alle water, en genadiglijk eenige bepaalde rechten aan zijn onderzaten toekent naar zijn welbehagen. Eigenlijk spreekt zulks ook wel vanzelf; want de vorst wist amper, wat dit oude volksrecht zijner onderzaten inhield, interesseerde zich daarvoor in geenen deele, en lijfde het dan ook niet bij zijn eigen opvattingen en instellingen nopens grondenrecht in.

4. Precies zóó als met het grondenrecht, staat het te dezẹn met dien hoeksteen van Vorstenlandsch agrarisch recht, de tegenstelling tusschen koeli's kentjeng en andere bewoners des lands. Ook deze tegenstelling is allerminst door den vorst'geschapen; het is het oudinheemsche kerndorperschap, dat vermoedelijk heel Indonesië en in elk geval heel het rechtstreeksch gebied op Java doordringt, en één der drie dorpsstanden - "de vanouds in het dorp thuisbehoorenden - - aanwijst als alle lusten genietend, maar dan ook alle lasten dragend. In stede van door het 
vorstenbestuur geschapen en uit het vorstenrecht verklaarbaar te zijn, is de inzetting van den koeli kentjeng juist aangetast, toegetakeld, tot onkenbaarwordens toe misvormd door 's vorsten maatregelen. $\mathrm{Al}$ evenmin laat zich uit vorstenrecht verklaren, welke inkomsten het dorpshoofd vanouds geniet (al kreeg later het vorstenbestuur daarop invloed); al evenmin laat zich uit vorstenrecht verklaren, waarom het grondenrecht van het Soendaland zoo verschillend is geworden van dat van Middelen Oost-Java, en ook de om hulp aangegrepen stroohalm van moslimsche tegenover Hindoesche inwerking kan dit raadsel niet oplossen, welks beantwoording uitsluitend te zoeken is bij het oudinheemsche beschikkingsrecht, hetwelk op Middel-Java $110 \mathrm{~g}$ krachtig is en op West-Java weggesleten.

5. Het zoogenaamde "communaal bezitrecht» van Java (dat als bezitrecht toekomt aan anderen dan de gemeente, en als recht der gemeente een ander recht is dan bezitrecht) kent ongetwijfeld de "vaste» bouwvelden der dorpsgenooten als ouder dan de "wisselende", en heeft deze vervorming ten nadeele der bevolking ongetwijfeld zich zien voltrekken onder invloed van het vorstenbestuur, gelijk later - en erger - van het gouvernement. Maar het recht zelf der dēsa is alweer niets anders dan het oudinheemsche beschikkingsrecht in zijn werking over cultuurgrond; en het terugvallen van onbeheerd geraakten cultuurgrond onder het onbelemmerde beschikkingsrecht der dorpsgemeente, welk terugvallen zoozeer heeft meegewerkt om dit "communaal bezit" te doen ontstaan en toenemen, is uit vorstenrecht niet te verklaren. Júist dat het beschikkingsrecht in het Soendaland wegsleet, en dat het terugvallen van cultuurgrond daar maar zelden kon voorkomen door het aansterken van het inlandsch bezitrecht, heeft de invoering van "communaal bezit» op West-Java zoogoed als onmogelijk gemaakt.

6. Het agrarisch eigendomsrecht van 1872 - dat ingewikkeld en nutteloos gouvernementsbedenksel - te vergelijken met het recht op landheergronden in de Kedoe en in Banten (en op Lombok, en elders op Java) kan alleen verwarrend werken. De twee instituten hebben gelijkenis, maar geenerlei verwantschap. Het eerste verbeeldt trouwens te werken voor den grooten drom der boerenbevolking; het tweede werkte alleen voor enkele hooge gunstelingen der vorsten.

7. Ook een beroep op Hindoesche werken ten gunste van Dl. 74 . 
het agrarisch vorstenrecht van Java kan alleen verwarren. Niet enkel omdat dit Hindoerecht hier aan de bevolking even vreemd gebleven is als op Bali, en ook aan de latere vorsten zelf wel nauwelijks bekend zal zijn geweest. Maar de paar plaatsen uit Hindoerechtsboeken, die men altoos weer aanhaalt, bewijzen niets; want hetzelfde woord, waarmede daarin gezegd wordt, dat de vorst "eigenaar" is van allen grond, wordt straks in die zelfde werken gebezigd om te zeggen, dat de inlandsche landbouwer "eigenaar s is van zijn grond of dat de goden "eigenaar" zijn van allen grond. Van een oppereigendom van den vorst boven een lager recht der grondbezitters blijkt uit die teksten volstrekt niets; en Kern ontkent zoowel voor Engelsch-Indië als voor Java, dat het Hindoerecht zoo iets medebrengt.

8. Tot dusver bleek niet veel van vorsteninvloed op het grondenrecht. In de buitenprovinciën van het Mataramsche rijk (dus ongeveer in de tegenwoordige gewesten Madoera, Soerabaja, Rembang, Semarang, Pekalongan, Kediri, Madioen en Banjoemas) heeft het vorstenbestuur er niet aan kunnen denken het agrarisch recht des volks omver te werpen. Het moge zijn, dat in de omgeving van Soerabaja de vorsteninvloed te dezen sterk en ontwrichtend is geweest -- zulke gegevens zijn natuurlijk goud waard - : daaruit te besluiten, dat overal in alle buitenprovinciën dit de toestand tijdens Mataram was, heeft geen grond. Stellig mag niet als bewijs worden aangevoerd, dat de vorst aldaar toch zijn vorstelijke landrente (padjeg boemi, padjeg sawah) hief - deden vorsten op Bali, op Zuid-Celebes en elders niet evenzoo? - en dat hij zich nu en dan zeggenschap over grond aanmatigde voor gunstbetoon, godsdienstige doeleinden, enz. Want daarbij bleef het. Het Eindresumé toont duidelijk, dat het inlandsch bezitrecht van grond geen schepping is van ons gezag, maar in den heelen vorstentijd bestond. Zelfs sloot Mataram, voor de aanwijzing van wie landrente- en dienstplichtig zouden zijn in de buitenprovinciën, volkomen aan op de oude dorpsinzettingen ten aanzien van het dragen van dorpslasten (het onderscheid maken tusschen de drie dorpsstanden); ook maakten Matarams provinciehoofden hier voor de inning gebruik van de hoofden der inheemsche dorpsgemeenten, niet van vorstelijke rentmeesters (bekels) met vorstelijke ambtsvelden. In de Preanger en in Banten is van inbreuk op het volksgrondenrecht door de hooge Preanger regenten of door den Bantenschen 
sultan zelfs in het ommeland zijner hofstad maar weinig sprake.

9. Van wien is dan het heilloos uitdenksel, het grondenrecht van Java's bevolking te gaan zoeken in den geheel exceptioneelen toestand der Vorstenlanden? Raffles heeft dat uitgedacht; gelijk later Van den Bosch zijn verwarde theorieën over het volksrecht grondvestte op wat hij meende, dat de Preanger te zien gaf, en op wat hij, naar Raffles' voorbeeld, meende te mogen generaliseeren. $\mathrm{Er}$ is voor lateren geen reden, deze ongerijmde voorbeelden te volgen; het pleit tegen ons, indien we ons nu nog, na honderd jaar, door Raffles' vergissing van de wijs laten brengen.

10. Of bewijst het heffen van padjeg boemi op zich zelf reeds, dus oqk voor de buitenprovinciën, dat er tusschen vorst en bevolking een deelbouwverhouding bestaat of althans, zoolang de belasting geïnd werd in product, bestaan heeft? Mag men uit het oogstdeel, dat geheven werd hetzij als percentage van den oogst (Preanger, Banten) hetzij naar de in oostersche vormen geschatte productiviteit van den grond (Bali, Mataram), het gevolg trekken, dat de vorst-eigenaar zijn cultuurgrond uitgaf in deelbouw of in veldhuur? De onhoudbaarheid van deze opvatting komt het duidelijkst uit op Zuid-Celebes, omdat daar de belasting, door de vorsten geheven van naar inlandsch recht bezeten velden, en de deelbouwopbrengst, door de vorsten genoten van in deelbouw uitgegeven vorstengrond (ornamentsvelden), bleven aangeduid met verschillende termen, zelfs al was het genoten bedrag gelijk en gelijksoortig. Op Java kan men helaas dit eenvoudig hulpmiddel niet gebruiken; want padjeg kan er zoowel landbouwbelasting (landrente) als pachtsom (huursom) beteekenen. Doch mocht men triomfant willen wijzen op gevallen, waarin wellicht ook voor de buitenprovinciën de belasting als maron (deelbouwopbrengst) wordt aangeduid - niet waarschijnlijk, daar zij hun belasting sinds lang afdroegen in geld -, dan verliest dit argument al zijn schijnwaarde, zoodra men bedenkt, dat het Javasche spraakgebruik de termen maron en memaro bezigt voor allerlei figuren, die met deelbouw niets anders gemeen hebben dan het opbrengen van een evenredig oogstdeel: maron als huldegift aan het dorpsbestuui, maron als recognitie wegens beschikkingsrecht voor het bewerken van akkers, maron als uitkeering aan een leidingbezitter, maron als belooning van Soendasche dienstplichtigen, die gedwongen zijn bepaalde sawahs te bewerken tegen genot 
van zoodanig loon. Dat ook in ons geval geen sprake is van deelbouw, blijkt hieruit, dat de echte deelbouwtransactie na afloop van den oogst of van het oogstjaar kan worden afgebroken door elke van beide partijen, terwijl het grondrecht van de padjegbetalende bevolking der buitenprovinciën alleen kon worden te niet gedaan in een (door den vorst verruimde) reeks van gevallen.

11. Beperkte zich dus voor het overgroote deel van Java 's vorsten invloed op het grondenrecht des volks tot padjegheffing en zulke zaken, het agrarisch recht der buidige Vorstenlanden daarentegen is inderdaad door het vorstenbestuur ontwricht. Dáár inderdaad is de vorst, door usurpatie, geworden tot den eigenaar-machthebbende over allen grond; dáár inderdaad zijn beschikkingsrecht, genotrecht, voorkeurrecht, weiderechț enz. voor den adem zijner neusgaten bezweken, en is het bezitrecht gedegradeerd tot een slap en wankel bouw-, bebouwings- of bewerkingsrecht. Een zelfde verschijnsel dus als wat het Bataksche Timoerland, wat Siak tegenover het heidensche deel zijner onderzaten, wat Ternate, Lombok, Bangli vertoont. Maar zelfs hier komt - gelijk in het geval van de koeli's kentjeng ook het agrarisch volksrecht van Indonesië door de scheuren van het vorstenkleed heengluren; en in Kedoe-Bagelēn is, sinds ze aan het kerngebied van Mataram onttrokken werden en bij het gouvernementsgebied gevoegd $(1812,1831)$, zoowaar het beschikkingsrecht met al die overige inheemsche bevolkingsrechten weer op den ouden voet herleefd. Aan toedoen van het gouvernement valt niet te denken, want er zijn rechten bij, waarvan de bureau's in Indië geen notie hadden, tegen welker erkenning zij zich verzetten met hand en tand, en die zij dus onmogelijk kunnen hebben aangekweekt.

12. Voor deze laatste streken, maar ook alleen voor deze laatste (de Vorstenlanden van nu), heeft derhalve een onderzoek naar 's vorsten rechtsopvattingen en rechtsinstellingen groote waarde. Hier is 's vorsten grondeigendom de practische (niet eens de historische) basis; hier heft hij zijn padjeg als een pachtsom; hier beschikt hij over de grondrechten des volks meer of min naar willekeur. Zelfs hier bestaat tusschen hem en zijn onderzaten geen deelbouwverhouding, ook al moge het woord maron en het woord maron-stelsel in zwang zijn voor betaling naar het product; evenmin als op Lombok, evenmin als op die particuliere landen beoosten de Tjimanoek, welker toestand te dezen 
erkend wordt als analoog, en waarvoor de rechtspraak nog

- onlangs met reden uitmaakte, dat de opgezetene er een bestendig bouwrecht heeft en niet maar deelbouwer of huurder is (al drukte zij dit westersch en onbeholpen uit in de woorden, dat de bevolking geen "persoonlijk recht", maar een "zakelijk bezitsrecht, heeft).

13. Naar aansluiting bij "het oude Javaansch-agrarische recht" heeft Raffles evenmin getaald als de compagnie zulks na 1748 deed voor haar gouvernement van Java's Noordoosthoek. Als hij in 1810 (na Malaka) vier maanden te gast is bij lord Minto en er het nieuwe landrentestelsel van Bengalen en omgeving hetwelk aansluit op het oude belastingstelsel der Noordindische vorsten - nader. leert kennen, besluit hij dit Noordindische landrentestelsel (met weglating van de grootpachters, en met vestiging van grondeigendom in den souverein) over te planten naar Java. Hij doet daardoor juist het omgekeerde van wat ginds Warren Hastings en lord Cornwallis hebben gewild of gedaan: hij neemt juist nict de vorstelijke landrente des lands (buitenprovinciën en West-Java) tot grondslag en uitgangspunt, maar phantaseert een gloednieuwe landrentebelasting naar vreemd (Voorindisch) model. In plaats van de oudinheemsche padjeg van Java, die, mooi of niet, een belasting naar grondslagen was, stelt hij zijn nieuwe padjeg, die in de practijk juist géén belasting was, maar willekeur zonder grondslagen, halen zooveel men halen kon. Het eenige stuk van Java, waar vóór 1907 een landbouwbelasting heeft bestaan voor inlanders, is de Preanger, omdat Raffles' ideeën daar noch vóór noch na 1871 hebben gewerkt. En dat noemden de gedweeë naschrijvers van later, dat het regulier belasten van den inlandschen landbouw op Java begint met Raffles; dat heette nu een vrucht van het door Raffles ingestelde onderzoek naar het grondenrecht van Java, waarbij wij goed zouden doen ons aan te sluiten.

14. De maatstaf van Van den Bosch voor het belasten van Java's landbouwende bevolking, nl. het aanvaarden van één vijfde van het product als aandeel van de hooge overheid, behoeft niet te worden opgevat als afwijking van een Vorstenlandschen maatstaf. Hij kan gekozen zijn op voorbeeld van den maatstaf van West-Java: in Banten toch bedroeg van de belaste sawahs in het kerngebied 's vorsten heffing één vijfde (voorheen één tiende), in de Preanger één tiende, in Tjerbon een fixum; nergens 
de twee vijfden van Mataram. Toen Daendels een landrente ontwierp voor Banten, volgde hij dit Noordbantensche één vijfde na; en Van den Bosch ging den weg van Daendels.

15. De illusie, alsof Raffles' met de Vorstenlanden "gestaafde» theorie nopens oppereigendom van den lande over inlandsche bouwvelden op Java het laatste woord zal zijn in deze materie, wordt wreed verstoord. Nadat reeds tal van malen door schrijverszonder-invloed is geprotesteerd, wordt thans de theorie verworpen door een van de raadslieden der regeering in agrarische zaken, mr. Nolst Trenité. In een praeadvies van 1917 voor de Nederlandsch-Indische Juristen-Vereeniging verwerpt hij die leer niet slechts voor een gedroomde toekomst, maar zelfs - wat sterker is - voor het thans geldend recht, ondanks de domeinverklaring van 1870 .

16. Samenvatting leidt tot deze slotsom:

a. voor de kennis van het oudinheemsche grondenrecht van Java's bevolking is een uiteenzetting van de Mataramsche vorstenopvattingen en -instellingen van niet het minste belang, doch alleen een ernstig gevaar; allerminst een fundament, allerminst een albeheerschende cardinale zaak;

$b$. voor de kennis van de vorstelijke landbouwheffingen op Java is een uiteenzetting van de Mataramsche vorstenopvattingen en -instellingen van waarde, mits men vooral niet doe, alsof voor de buitenprovinciën van Mataram hetzelfde gold als voor het kerngebied des rijks, en mits men niet vergete, dat er ook andere vorstenrijken dan Mataram zijn geweest;

c. voor de kennis van het grondenrecht en de landbouwheffingen in de tegenwoordige Vorstenlanden is een degelijke uiteenzetting van de Mataramsche vorstenopvattingen en -instellingen van zeer groote waarde, mits men niet afga op woorden, die "deelbouw" noemen wat geen "deelbouw" is. 